\title{
The Effects of Stretching and Strengthening Exercise on the Pain, Pelvic Tilt, Functional Disability Index, and Balance Ability of Patients with Chronic Lower Back Pain
}

Tae Woo Kang ${ }^{1}$, Beom Ryong Kim²

'Department of Physical Therapy, College of Health and Welfare, Woosuk University, Wonju; ${ }^{2}$ Department of Physical Therapy, Design Hospital, Jeon ju, Korea

Purpose: This study examined the effects of stretching and strengthening exercises on the pain, pelvic tilt (PT), functional disability, and balance of patients with chronic lower back pain (CLBP).

Methods: A total of 42 patients with CLBP were randomly divided randomly into either experimental group I ( $E G I, n=21)$, who received stretching exercise, or experimental group II ( $E G I I, n=21)$, who received strengthening exercise. Both interventions were applied three times a week for eight weeks. Assessments were made with a visual analogue scale (VAS), PT, Oswestry disability index (ODI), and Berg's balance scale (BBS) before and after the eight weeks intervention period. A paired t-test was conducted to compare the within-group changes before and after the intervention. An independent t-test was used compare the between-group difference. The statistical significance level was set to $\alpha=0.05$ for all variables.

Results: The EG I and II showed significant within-group changes in the VAS, PT, ODI, and BBS $(p<0.05)$. The changes in VAS, PT, ODI, and BBS were similar regardless of the exercise form.

Conclusion: In this study, the application of stretching and strengthening exercise for subjects who complain of CLBP was effective in changing the level of pain, PT, functional disability, and balance.

Keywords: Balance ability, Functional disability index, Lower back pain, Pelvic tilt

서 론

직업과 관련된 근골격계 질환은 다양한 위험 요인(risk factors)에 의해 발생된다. 위험 요인은 크게 개인, 작업, 사회 요인으로 구분되며, 작업 요인이 가장 높은 근골격계 질환의 위험 요인으로 보고되고 있다. 특 히 단순하고 반복적인 작업 요인은 부적절한 자세를 초래하며, 허리 통증(lower back pain)을 유발시키는 원인이 된다. 허리통증은 전체 인구의 $80 \%$ 가 생애 중 한 번 이상은 경험하고, 치료실을 찾는 가장 흔 한 원인 중 하나이다. ${ }^{3}$ 이 중에 완전히 회복되지 않고, 12 주 이상 통증 이 지속되는 경우를 만성 허리통증(chronic lower back pain)이라 한 다. 통증이 만성화되면 허리부위의 가동성과 안정성 및 근력이 감소 되고, 고유수용감각의 변화로 협응력의 저하와 다양한 신체기능의 손상이 발생한다. ${ }^{5}$

허리통증의 원인을 근육과 자세의 불균형이라 고려할 때6 허리통
증 관리를 위해서는 근력강화와 바른 자세유지 및 균형능력을 향상 시킬 수 있는 중재프로그램이 병행되어야 한다. 균형은 기저면(base of support, BOS)과 안정성의 제한(limits of stability, LOS) 내에 중력중 심(center of gravity, $\mathrm{COG})$ 을 유지하는 신체능력이다. 균형을 유지하 기 위해서는 말초와 중추신경계의 상호작용이 필수적이며, 말초신경 계는 피부와 통증에 대한 고유수용감각을 제공하는 체성감각, 환경 에 대한 정보를 제공하는 시각, 몸통과 머리위치에 대한 정보를 제공 하는 전정계로 구성된다. 중추신경계는 말초 요소로부터 입력된 정 보를 통합하여 자세조절과 몸통의 위치를 수행하는데 가장 적절한 근육의 반응을 선택하는 것 이다. ${ }^{10}$ 이와 같이 허리통증은 단순하게 통증만을 문제점으로 나타나지 않기 때문에 운동의 중요한 목표는 신체기능 회복과 균형능력의 향상이며, 이를 통해 자연스럽게 통증 을 감소시킬 수 있다."

Janda는 만성통증 증후군과 관련해 층 증후군(layer syndrome)과 
상 교차 증후군(upper crossed syndrome) 및 하 교차 증후군(lower crossed syndrome)의 패턴으로 구분하였다. 특히 하 교차 증후군에서 등쪽 면(dorsal side)에서 엉덩관절 굽힘근(hip flexors)과 등허리 폄근 (thoracolumbar extensors)의 긴장(tight)이 교차하고, 배쪽 면(ventral side)에서 엉덩관절 폄근(hip extensors)과 배근육(abdominals)의 약화 (weak)가 교차한다.12 이와 같은 엉덩관절의 가동범위와 근력 및 근육 길이의 불균형은 골반기울기(pelvic tilt)에 영향을 미치며 허리통증과 연관된다. ${ }^{13,14}$ 하 교차 증후군을 바탕으로 만성 허리통증환자를 대상 으로 적용한 연구들을 살펴보면, $\mathrm{An}$ 은 ${ }^{15}$ 넙다리뒤근육(hamstring muscles)을 신장한 결과 허리통증 감소와 허리 굽힘 동작에 향상을 보였으며, Kim과 Lee ${ }^{16}$ 은 배근육을 강화한 결과 통증과 폐 기능 및 기 능장애지수에 유의한 결과를 얻었고, 엉덩관절 폄근과 배근육의 약 화는 허리통증과 높은 관련성을 보고하였다.13,17 또한, 엉덩관절 굽힘 근의 신장은 허리통증 감소를 보고하였고, ${ }^{18}$ 배근육의 약화는 허리의 전만(lordosis)과 골반기울기를 증가시켜 허리통증을 유발할 수 있으 며, ${ }^{1}$ 엉덩관절 굽힘근과 등허리 폄근의 신장운동과 엉덩관절 폄근과 배근육 강화운동의 필요성을 시사한다.

이와 같이 허리주위의 긴장된 근육에 대한 신장운동과 약화된 근 육에 대한 강화운동을 통해서 허리통증과 관절가동범위 및 기능장 애지수에 효과적이라는 연구들이 발표되고 있지만, 만성 허리통증 환자에게 두 가지 유형의 운동을 적용하여 어떤 유형의 운동이 허리 통증, 골반기울기, 기능장애지수 및 균형능력 변화에 효과가 있는지 비교한 연구는 미비한 실정이다. 따라서 본 연구에서는 만성 허리통 증환자에게 엉덩관절 굽힘근과 등허리 폄근의 긴장된 근육에 대한 신장운동과 엉덩관절 폄근과 배근육의 약화된 근육에 대한 강화운 동을 통하여 허리통증, 골반기울기, 기능장애지수 및 균형능력에 미 치는 효과를 알아보고자 한다.

\section{연구 방법}

\section{1. 연구 대상}

본 연구에 필요한 적정 대상자 수는 G*power 3.1 프로그램으로 분석 하였다. 독립표본 $\mathrm{t}$-검정(independent t-test)에서 유의수준 0.05 , 큰 효 과크기(large effect size) $0.8,0.8$ (80\%)의 검정력(power)에서 실제 검정력 (actual power), 0.87 (80.7\%)을 유지하기 위해 필요한 표본수는 각 집단 별 21 명으로 총 42 명의 대상자를 선정하였다.

연구 대상자는 2018년 2월부터 10월까지 J시 소재 D병원 외래환자 로 12주 이상 허리통증을 호소한 40-50대 연령범위의 만성 허리통증 환자를 대상으로 하였다. 본 연구의 목적을 이해하고 연구에 참여하 기로 동의한 42 명을 대상으로 하였다. 이들을 각각 신장운동을 실시 한 실험군 I $(n=21)$ 과 강화운동을 실시한 실험군 II $(n=21)$ 으로 무작
Table 1. General characteristics of participants

$(n=42)$

\begin{tabular}{lccc}
\hline & $\begin{array}{c}\text { Experimental } \\
\text { group I }(\mathrm{n}=21)\end{array}$ & $\begin{array}{c}\text { Experimental } \\
\text { group II }(\mathrm{n}=21)\end{array}$ & $\mathrm{p}$ \\
\hline Sex (male/female) & $11 / 10$ & $9 / 12$ & 1.00 \\
Age $(\mathrm{yr})$ & $47.67(4.49)$ & $48.28(3.82)$ & 0.06 \\
Height $(\mathrm{cm})$ & $164.90(9.42)$ & $163.38(10.14)$ & 0.44 \\
Body weight $(\mathrm{kg})$ & $65.09(9.24)$ & $64.81(9.96)$ & 0.30 \\
Body mass index $\left(\mathrm{kg} / \mathrm{cm}^{2}\right)$ & $23.83(1.66)$ & $24.23(2.72)$ & 0.80 \\
Visual analogue scale $($ scores $)$ & $6.48(0.95)$ & $6.61(1.05)$ & 0.92 \\
Pelvic anterior tilting angle $\left(^{\circ}\right)$ & $15.03(1.28)$ & $14.86(1.50)$ & 0.23 \\
Oswestry disability index (scores) & $32.48(3.08)$ & $33.05(2.91)$ & 0.16 \\
Berg's balance scale (scores) & $42.86(2.22)$ & $43.14(2.13)$ & 0.11 \\
\hline
\end{tabular}

Data are mean (standard deviation).

Experimental group I: stretching exercise. Experimental group II: strengthening exercise.

위배정하였다.

제외기준은 다음과 같다. 1) 급성통증이나 지속적으로 심한 통증 을 가진 자, 2) 척추 분리증이나 전방전위증이 있는 자, 3) 신경학적으 로 감각이상이나 근육마비가 있는 자, 4) 정신적인 문제나 이해력이 부족하여 운동수행 능력이 어려운 자. 연구 대상자의 일반적 특성은 다음과 같다(Table 1).

\section{2. 실험 방법}

\section{1) 신장운동 프로그램}

신장운동 프로그램은 치료사에 의해 전형적인 정적 신장을 수행하 였다. 엉덩관절 굽힘근(hip flexors) 신장운동은 수정된 토마스 테스트 자세로 대상자는 테이블 끝 부분에 엉덩이를 위치시키고 바로 누운 자세에서 신장시키고자 하는 반대쪽 다리의 무릎 아래 부분을 가슴 앞으로 잡고, 신장시키고자 하는 다리의 무릎 위 부분을 치료사가 일 정한 힘으로 폄 시켜 신장 시켰다. 등허리 폄근(thoracolumbar extensors) 신장운동은 바로 누운 자세에서 대상자가 양쪽무릎 아래를 잡 은 상태에서 가슴 앞으로 잡아당기도록 하고, 치료사가 일정한 힘으 로 가슴 방향으로 밀어주어 등허리 폄근을 신장시켰다. 신장시키고 자 하는 부분에 약간의 불편함이 느껴질 때까지 계속 시행하였다. 신 장운동은 30 초간 10 세트씩 시행하였다. 세트 간 쉬는 시간은 10 초로 하였으며, 주 3 회 8 주간 시행하였다.

\section{2) 강화운동 프로그램}

강화운동 프로그램은 치료사에 의해 전형적인 몸통 안정화 운동을 수행하였다. 배근육 강화운동은 브레이싱운동(bracing exercise)을 시 행하였다. 운동의 방법은 대상자가 무릎을 90 도 구부리고 누운 자세 로 허리와 골반의 정렬을 맞춘 상태에서 압력생체되먹임기구(Stabilizer $^{\mathrm{TM}}$, Pressure Biofeedback Unit, USA)를 허리부위에 위치시킨 후 압 
력계의 압력을 $40 \mathrm{mmHg}$ 로 유지시켰다. 이후 복부에 힘을 주어 복부 에 모든 근육이 빠르게 수축하도록 하여 압력계의 압력을 $70 \mathrm{mmHg}$ 로 상승시켜서 유지하도록 하였다. 엉덩관절 폄근 강화운동은 브릿 지 운동(bridge exercise)을 시행하였다. 운동의 방법은 대상자가 무릎 을 90 도 구부리고 누운 자세로 허리와 골반의 정렬을 맞춘 상태에서 엉덩이를 들어올려서 유지하도록 하였다. 강화운동은 30 초간 10세트 씩 시행하였다. 세트 간 쉬는 시간은 10 초로 하였으며, 주 3 회 8 주간 시행하였다.

\section{3) 측정항목 및 방법}

(1) 허리통증의 측정

통증의 정도를 측정하기 위해 시각적 상사척도(visual analogue scale, $\mathrm{VAS}$ )를 이용하였다. 통증이 전혀 없는 상태는 0 , 통증이 최대로 있는 상태는 10 으로 하여 10 개의 구간이 표시된 종이 위에 직접 체크하도 록 하였다. 검사 재검사 간 신뢰도는 $\mathrm{r}=0.96$ 이다. ${ }^{20}$

\section{(2) 골반기울기의 측정}

골반기울기(pelvic tilt, PT)의 변화를 측정하기 위하여 Dartfish 소프트 웨어를 이용하였다. 먼저 대상자의 한쪽 위앞엉덩뼈가시(anterior superior iliac spine, ASIS)와 위뒤엉덩뼈가시(posterior superior iliac spine) 부위에 촬영 시 식별이 가능한 입체 스티커를 부착 후 카메라 렌즈의 높이를 대상자의 위앞엉덩뼈가시의 높이에 맞춰 높이를 조정하고 수 평이 맞춰진 카메라를 이용하여 시상면에서 대상자로부터 1미터 떨 어진 곳에서 촬영하였다. 촬영 시 대상자는 마음을 편안히 가지고 양 발은 평행하게 어깨넓이로 벌린 후 시선은 정면을 응시하도록 하였 다. 이렇게 촬영된 사진을 Dartfish 소프트웨어의 각도측정 기능을 이 용해 위앞엉덩뼈가시와 위뒤엉덩뼈가시에 가상의 선을 만든 후 지면 과수평선에 대한 각도를 측정하였다.

\section{(3) 기능장애지수의 측정}

허리통증에 의한 장애 정도를 평가하기 위해 오스웨스트리 허리통 증 장애지수(Oswestry disability index, ODI)를 이용하였다. ODI는 통 증 강도, 개인적 관리, 들기, 걷기, 앉아 있기, 서 있기, 잠자기, 성생활, 사회생활, 여행의 10 개 항목으로 각 항목의 수행 능력에 따라 0 점에 서 5점으로 6 가지 단계로 기술한다. ${ }^{21} \mathrm{ODI}$ 는 점수가 높을수록 장애 가 심한 것을 의미한다.

\section{(4) 균형능력의 측정}

균형능력을 측정하기 위해 버그균형척도(Berg's balance scale, BBS)를 이용하여 평가하였다. BBS는 14 개의 항목으로 앉기, 서기, 자세 변화 의 3 개의 영역을 최소 0 점에서 최대 4 점으로 적용되어 총점은 56 점으
로 높은 점수를 기록할수록 높은 균형능력을 평가 받는다. 검사 재검 사간 신뢰도는 $r=0.97-0.99$ 이다. ${ }^{22}$

\section{4. 통계처리}

본 연구를 위한 자료처리 방법은 Window용 통계프로그램 SPSS/PC Statistics 23.0 software (SPSS Inc, Chicago, USA)을 이용하여 통계 처리 하였다. 연구 대상자의 일반적인 특성을 Shapiro-wilk로 정규성 검정 을 하였고, 운동프로그램에 따른 운동 전과 후의 집단 내 허리통증, 골반기울기, 기능장애지수 및 균형능력에 변화를 비교하기 위하여 대응표본 t-검정(paired t-test)을 실시하였다. 실험군 I과 실험군 II의 집 단 간의 차이를 비교하기 위해 독립표본 t-검정(independent t-test)으 로 검정하였다. 모든 통계학적 유의수준은 $\alpha=0.05$ 로 설정하였다.

\section{결 과}

\section{1. 허리통증의 변화 비교}

신장운동과 강화운동에 따른 운동형태가 만성허리통증환자의 허리 통증에 미치는 영향을 알아보았다. 허리통증의 운동 전과 후 측정값 을 비교한 결과 신장운동 집단은 운동 전 $6.48 \pm 0.95$ 점에서 운동 후 $2.35 \pm 0.97$ 점으로 변화하여 집단 내에서 유의한 감소가 있었고 $(\mathrm{p}<0.05)$, 강화운동 집단은 운동 전 $6.61 \pm 1.05$ 점에서 운동 후 $2.86 \pm$ 0.57 점으로 변화하여 집단 내 유의하게 감소하였다 $(\mathrm{p}<0.05)$.

운동형태에 따른 운동 전 허리통증의 집단 간 차이는 없는 것으로 나타났으며, 허리통증의 변화량 차이는 집단 간 유의한 차이가 없었 다(Table 2).

\section{2. 골반기울기의 변화 비교}

신장운동과 강화운동에 따른 운동형태가 만성허리통증환자의 골반 기울기에 미치는 영향을 알아보았다. 골반기울기의 운동 전과 후 측 정값을 비교한 결과 신장운동 집단은 운동 전 $15.03 \pm 1.28$ 도에서 운 동 후 $12.30 \pm 1.17$ 도로 변화하여 집단 내에서 유의한 감소가 있었고 $(\mathrm{p}<0.05)$, 강화운동 집단은 운동 전 $14.86 \pm 1.50$ 도에서 운동 후 $11.86 \pm$ 1.49 도로 변화하여 집단 내 유의하게 감소하였다 $(\mathrm{p}<0.05)$.

운동형태에 따른 운동 전 골반기울기의 집단 간 차이는 없는 것으 로 나타났으며, 골반기울기의 변화량 차이는 집단 간 유의한 차이가 없었다(Table 2).

\section{3. 기능장애지수의 변화 비교}

신장운동과 강화운동에 따른 운동형태가 만성허리통증환자의 기능 장애지수에 미치는 영향을 알아보았다. 기능장애지수의 운동 전과 후 측정값을 비교한 결과 신장운동 집단은 운동 전 $32.48 \pm 3.08$ 점에 
Table 2. The comparison of changes in pain, pelvic tilt, functional disability index, and balance ability within and between groups

\begin{tabular}{|c|c|c|c|c|c|}
\hline & & Experimental & Experimental & t & $n$ \\
\hline & & Group I $(n=21)$ & Group II $(n=21)$ & $l$ & $p$ \\
\hline Visual analogue scale (scores) & Pre & $6.48(0.95)$ & $6.61(1.05)$ & & \\
\hline & Post & $2.35(0.97)$ & $2.86(0.57)$ & & \\
\hline & $t(p)$ & $13.38(0.00)^{*}$ & $15.84(0.00)^{*}$ & & \\
\hline & Change & $4.14(1.42)$ & $3.76(1.09)$ & 0.98 & 0.33 \\
\hline Pelvic anterior tilting angle $\left(^{\circ}\right)$ & Pre & $15.03(1.28)$ & $14.86(1.50)$ & & \\
\hline & Post & $12.30(1.17)$ & $11.86(1.49)$ & & \\
\hline & $t(p)$ & $11.58(0.00)^{*}$ & $13.48(0.00)^{*}$ & & \\
\hline & Change & $2.73(1.08)$ & $3.41(1.16)$ & -1.95 & 0.06 \\
\hline Oswestry disability index (scores) & Pre & $32.48(3.08)$ & $33.05(2.91)$ & & \\
\hline & Post & $21.62(2.80)$ & $21.86(4.19)$ & & \\
\hline & $t(p)$ & $16.12(0.00)^{*}$ & $15.28(0.00)^{*}$ & & \\
\hline & Change & $10.86(3.09)$ & $11.19(3.35)$ & -0.33 & 0.74 \\
\hline Berg's balance scale (scores) & Pre & $42.86(2.22)$ & $43.14(2.13)$ & & \\
\hline & Post & $52.05(2.69)$ & $53.48(1.47)$ & & \\
\hline & $t(p)$ & $-13.41(0.00)^{*}$ & $-21.99(0.00)^{*}$ & & \\
\hline & Change & $-9.19(3.14)$ & $-10.33(2.15)$ & 1.38 & 0.18 \\
\hline
\end{tabular}

Data are mean (standard deviation).

Experimental group l: stretching exercise. Experimental group II: strengthening exercise. ${ }^{*} \mathrm{p}<0.05$.

서 운동 후 $21.62 \pm 2.80$ 점으로 변화하여 집단 내에서 유의한 감소가 있었고 $(\mathrm{p}<0.05)$, 강화운동 집단은 운동 전 $33.05 \pm 2.91$ 점에서 운동 후 $21.86 \pm 4.19$ 점으로 변화하여 집단 내 유의하게 감소하였다 $(\mathrm{p}<0.05)$.

운동형태에 따른 운동 전 기능장애지수의 집단 간 차이는 없는 것 으로 나타났으며, 기능장애지수의 변화량 차이는 집단 간 유의한 차 이가 없었다(Table 2).

\section{4. 균형능력의 변화 비교}

신장운동과 강화운동에 따른 운동형태가 만성허리통증환자의 균형 능력에 미치는 영향을 알아보았다. 균형능력의 운동 전과 후 측정값 을 비교한 결과 신장운동 집단은 운동 전 $42.86 \pm 2.22$ 점에서 운동 후 $52.05 \pm 2.69$ 점으로 변화하여 집단 내에서 유의한 증가가 있었고 $(\mathrm{p}<0.05)$, 강화운동 집단은 운동 전 $43.14 \pm 2.13$ 점에서 운동 후 $53.48 \pm$ 1.47 점으로 변화하여 집단 내 유의하게 증가하였다 $(\mathrm{p}<0.05)$.

운동형태에 따른 운동 전 균형능력의 집단 간 차이는 없는 것으로 나타났으며, 균형능력의 변화량 차이는 집단 간 유의한 차이가 없었 다(Table 2).

\section{고 찰}

신장과 강화운동이 허리통증(VAS), 골반기울기(PT), 기능장애지수 (ODI) 및 균형능력(BBS)에 미치는 영향에 대하여 다음과 같이 논의 를하고자한다.
Lee와 Song 은 ${ }^{18} 20-40$ 대 연령범위의 허리통증환자 40 명을 대상으 로 4 주 동안 12 회 엉덩관절 굽힘근의 수동과 능동 신장운동을 실시 한 결과 허리통증 감소에 향상된 결과를 보였고, $\mathrm{An}$ 은 ${ }^{15} 20-60$ 대 연령 범위의 만성 허리통증환자 40 명을 대상으로 넙다리뒤근육 신장운동 을 실시한 결과 집단 내·간 허리통증 감소에 향상된 결과를 보였다. 본 연구에서도 8 주 동안 24회 실시한 신장과 강화운동 집단 모두에 서 허리통증이 운동 전과 후에 유의한 감소를 보였다. Kwag과 $\mathrm{Lim}^{23}$ 은 허리통증으로 치료를 받고 있는 30-55세 연령범위의 제조업체 남 성근로자 30 명을 대상으로 강화운동 집단 10 명, 신장운동 집단 10 명, 신장과 강화운동 집단 10 명으로 무작위 배정하여 6주 동안 18 회 중 재한 결과 모든 운동 집단에서 중재 전과 후에 허리통증의 감소에 유 의한 향상으로 보였으며, 집단 간 비교에서는 신장과 강화 운동을 실 시한 집단에서 더욱 효과적인 결과를 보였으며, 본 연구의 중재방법 을 지지해준다. 이와 같은 결과는 신장운동을 통해 긴장된 등허리 폄 근과 엉덩관절 굽힘근의 길이확보와 강화운동을 통해 약화된 배근 육과 엉덩관절 폄근의 강화로 골반기울기와 허리부분의 전만 감소로 척추에 가해지는 압력을 줄여주어 허리통증이 경감된 것으로 사료 된다. ${ }^{24}$

골반기울기는 위앞엉덩뼈가시와 위뒤엉덩뼈가시을 잇는 선과 수 평면(horizontal plane) 간의 각이다. ${ }^{25}$ 골반기울기의 평균값은 $11.3 \pm 4.3$ 도이다. ${ }^{26}$ 본 연구에서도 8 주 동안 24 회 실시한 신장과 강화운동 집단 모두에서 골반기울기는 운동 전과 후에 유의한 향상을 보였다. 이러 한 결과는 6주 동안의 허리강화운동을 통해 허리전만각도(lumbar 
lordosis angle)가 정상 성인의 평균값에 가까워졌다고 보고한 $\mathrm{Kim}^{27}$ 의 연구와 일치하였다. 또한, Park 등 28 은 만성 허리통증환자 46 명을 대상 으로 12 주간 주 3 회 일반물리치료와 슬링운동을 통한 강화운동을 실시한 결과 슬링운동군에서 허리전만각도와 골반기울기는 정상 평 균값에 가까운 변화를 보였다. 이러한 선행연구들과 본 연구의 결과 는 허리부위의 안정화와 근력의 강화로 인하여 시상정렬의 회복에 영향을 미쳤다고 사료된다. 또한, 신장운동 집단에서도 전방기울기가 정상인의 평균값에 가까워짐을 볼 때 신장운동이 효과가 없었다고 는 단정할 수 없다. 골반전방기울기의 향상을 위해 신장과 강화운동 을 병행할 필요가 있다고 판단된다.

$\operatorname{Kim}$ 등 29 은 허리통증을 호소하는 요양과 재활 병원 물리치료사 43 명을 대상으로 허리 강화와 신장운동이 포함된 실험군과 작업관련 근골격계질환에 대한 교육을 실시한 대조군으로 무작위 배정하여 12 주 동안 실시한 결과 실험군에서 집단 내·간 기능장애지수의 변화 에 향상된 결과를 보였고, Nagrale 등 ${ }^{30}$ 은 $18-60$ 세 연령범위의 허리통 증환자 60 명을 대상으로 슬럼프신장운동과 안정화 운동을 실시한 실험군과 안정화 운동만 실시한 대조군으로 무작위 배정하여 중재 한 결과 실험군에서 집단 내·간 기능장애지수 변화에서 향상된 결과 를 보였다. 본 연구에서도 8 주 동안 24 회 실시한 신장과 강화운동 집 단 모두에서 기능장애지수가 운동 전과 후에 유의한 감소를 보였다. 그러나 집단 간에는 차이를 보이지 않았다. 이러한 결과는 반복된 신 장과 강화운동을 통해 근육길이 및 근력의 불균형이 해소되어 척추 의 운동범위 증가와 통증의 감소로 ${ }^{31}$ 기능장애지수 향상에 영향을 미치는 것으로 생각되며, 집단 간 비교에서 차이를 보이지 않은 것으 로 사료된다.

$\operatorname{Kim}$ 등 $^{32}$ 은 20 대 초반의 만성허리통증환자 34 명을 대상으로 5 주 동안 10 회 허리안정화훈련을 실시한 결과 동적과 정적 균형능력에 향상된 결과를 보였고, Park과 $\mathrm{Kim}^{33}$ 은 20-40대 연령범위의 만성허리 통증환자 35 명을 대상으로 8주 동안 24 회 허리안정화훈련을 실시한 결과 균형능력에 향상을 보였으며, Jeon ${ }^{7}$ 은 만성허리통증을 호소하 는 노인환자 34 명을 대상으로 6주 동안 18 회 PNF 훈련을 실시한 결과 동적과 정적 균형능력에 향상을 보였다. 본 연구에서도 8 주 동안 24 회 실시한 신장과 강화운동 집단 모두에서 균형능력이 운동 전과 후 에 유의한 향상을 보였다. 이러한 결과는 반복된 엉덩관절 굽힘근의 신장으로 가동범위가 확보되고, 배근육과 엉덩관절 폄근 강화운동 이 배곧은근, 배바깥빗근, 배속빗근, 배가로근, 큰볼기근의 수축력과 근력이 운동조절과 학습에 의해 증가되어 ${ }^{24}$ 균형능력 향상에 영향을 미치는 것으로 생각된다.

본 연구의 운동을 통한 등허리 폄근과 엉덩관절 굽힘근의 길이확 보와 배근육과 엉덩관절 폄근의 강화는 허리통증, 기능장애지수, 균 형능력, 골반기울기의 변화에 효과적이었고, 신장운동과 강화운동
의 운동 전과 후의 허리통증, 기능장애지수, 균형능력, 골반기울기 변 화량에서 집단 간 유의한 차이가 없어 운동형태에 따른 효과를 규명 하기에는 어려움이 있었다. 그러나 신장운동과 강화운동은 허리통 증 예방을 하는데 매우 중요한 요소임을 확인하였고, 이러한 결과를 바탕으로 향후에도 임상에서 신장과 강화운동을 활용한 다양한 연 구가 필요할 것으로 사료된다.

본 연구의 제한점으로 첫째, 신장과 강화운동이 병합된 집단이 없 기 때문에 이에 대한 각 집단 간에 효과를 확인할 수 없었다. 둘째, 대 조집단이 없기 때문에 운동형태에 대한 효과를 확인할 수 없었다. 차 후에는 이러한 제한점이 보완된 연구가 이루어져야 할 것이다.

\section{REFERENCES}

1. Kumar S. Theories of musculoskeletal injury causation. Ergonomics. 2001;44(1):17-47.

2. Chung MK, Lee I, Yeo YS. Physiological workload evaluation of screw driving tasks in automobile assembly jobs. Int J Ind Ergon. 2001;28(34):181-8.

3. O'Sullivan PB. Lumbar segmental 'instability': clinical presentation and specific stabilizing exercise management. Man Ther. 2000;5(1):2-12.

4. Hides JA, Richardson CA, Jull GA. Multifidus muscle recovery is not automatic after resolution of acute, first-episode low back pain. Spine. 1996;21(23):2763-9.

5. Koumantakis GA, Watson PJ, Oldham JA. Trunk muscle stabilization training plus general exercise versus general exercise only: randomized controlled trial of patients with recurrent low back pain. Phys Ther. 2005;85(3):209-25.

6. Hyoung HK. Effects of a strengthening program for lower back in older women with chronic low back pain. J Korean Acad Nurs. 2008;38(6): 902-13.

7. Jeon JK. The effects of combination patterns exercise of proprioceptive neuromuscular facilitation on balance in chronic low back pain elderly patients. J Digital Convergence. 2013;11(4):361-8.

8. Nichols DS, Miller L, Colby LA et al. Sitting balance: its relation to function in individuals with hemiparesis. Arch Phys Med Rehabil. 1996; 77(9):865-9.

9. Alexander KM, Kinney LaPier TL. Differences in static balance and weight distribution between normal subjects and subjects with chronic unilateral low back pain. J Orthop Sports Phys Ther. 1998;28(6):378-83.

10. McCollum G, Shupert CL, Nashner LM. Organizing sensory information for postural control in altered sensory environments. J Theor Biol. 1996;180(3):257-70.

11. Rantanen P. Physical measurements and questionnaires as diagnostic tools in chronic low back pain. J Rehabil Med. 2001;33(1):31-5.

12. Frank C, Page P, Lardner R. Assessment and treatment of muscle imbalance: the Janda approach. Champaign, Human Kinetics, 2009.

13. Nourbakhsh MR, Arab AM. Relationship between mechanical factors and incidence of low back pain. J Orthop Sports Phys Ther. 2002;32(9): 447-60.

14. Van Dillen LR, McDonnell MK, Fleming DA et al. Effect of knee and 
hip position on hip extension range of motion in individuals with and without low back pain. J Orthop Sports Phys Ther. 2000;30(6):307-16.

15. An CS. The effects of hamstring stretching exercise on angle of lumbar flexion and pain reduction with chronic low back patients. J Korean Phys Ther. 2005;17(4):559-67.

16. Kim BR, Lee HJ. Effects of proprioceptive neuromuscular facilitationbased abdominal muscle strengthening training on pulmonary function, pain, and functional disability index in chronic low back pain patients. J Exerc Rehabil. 2017;13(4):486-90.

17. Lee P, Helewa A, Goldsmith $\mathrm{CH}$ et al. Low back pain: prevalence and risk factors in an industrial setting. J Rheumatol. 2001;28(2):346-51.

18. Lee JJ, Song BB. The effects of the passive and active stretching exercises of iliopsoas muscles on low back pain patients. J Spec Educ Rehabil Sci. 2015;54(2):291-307.

19. Rone-Adams SA, Shamus E, Hileman M. Physical therapists' evaluation of the trunk flexors in patients with low back pain. IJAHSP. 2004;2(2):3.

20. Lingjærde O, Føreland AR. Direct assessment of improvement in winter depression with a visual analogue scale: high reliability and validity. Psychiatry Res. 1998;81(3):387-92.

21. Fairbank JC, Pynsent PB. The Oswestry disability index. Spine. 2000; 25(22):2940-53.

22. Berg K, Wood-Dauphinee S, Williams J. The balance scale: reliability assessment with elderly residents and patients with an acute stroke. Scand J Rehabil Med. 1995;27(1):27-36.

23. Kwag KI, Lim JH. The effects of stabilization exercise and stretching exercise on muscle strength and pain of patients with lower pack pain. J Korean Acad Clin Electrophys. 2011;9(2):39-46.

24. Bong SY, Kim YJ, Kang MG et al. Effects of proprioceptive neuromuscular facilitation exercise on forced expiratory volume at one second, pain, and functional disability index of chronic low back pain patients. PNF \&
Mov. 2016;14(3):185-93.

25. Levangie PK, Norkin CC. Joint structure and function: a comprehensive analysis. Philadelphia, FA Davis, 2011.

26. Levine D, Whittle MW. The effects of pelvic movement on lumbar lordosis in the standing position. J Orthop Sports Phys Ther. 1996;24(3): 130-5.

27. Kim BG. The influence of exercise for trunk stabilizing on lumbosacral region angle in low back pain patients. Daegu University. Dissertation of Doctorate Degree. 2006.

28. Park SJ, Shin JY, Hwang R. Sling exercise effects on sagittal alignment of chronic low back pain patients. Korean J Phys Education. 2015;54(1): 527-34.

29. Kim JH, Hur JG, Ko TS et al. The effect of exercise program on work-related back pain in physical therapists. J Korean Acad Med Ther Sci. 2009;1(1):15-23.

30. Nagrale AV, Patil SP, Gandhi RA, et al. Effect of slump stretching versus lumbar mobilization with exercise in subjects with non-radicular low back pain: a randomized clinical trial. J Man Manip Ther. 2012;20(1):3542.

31. Gawda P, Dmoszynska-Graniczka M, Pawlak H et al. Evaluation of influence of stretching therapy and ergonomic factors on postural control in patients with chronic non-specific low back pain. Ann Agric Environ Med. 2015;22(1):142-6

32. Kim GY, Ahn CS, Kim SS. The effects of 3-dimensional lumbar stabilization exercise have an effect on the improvement of pain and static or dynamic balance ability in 20's age group with low back pain. J Korean Soc Phys Med. 2011;6(2):235-46.

33. Park J, Kim K. The analysis of stabilization exercise on lumbar extension strength, balance ability in adult female of chronic back pain patients. Korean J Sports Sci. 2012;21(21):1129-38. 